\title{
Vascular Medicine
}

http://vmj.sagepub.com/

\author{
Renal arteriovenous fistula \\ Johannes Jacobi, Karl F Hilgers, Werner Lang, Kai-Uwe Eckardt and Michael Uder \\ Vasc Med 2010 15: 433 \\ DOI: $10.1177 / 1358863 \times 10376000$
}

The online version of this article can be found at:

http://vmj.sagepub.com/content/15/5/433

\author{
Published by: \\ (A) SAGE \\ http://www.sagepublications.com \\ On behalf of:

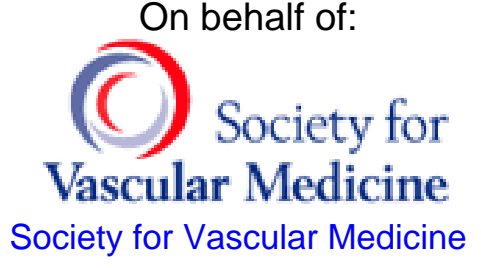

Additional services and information for Vascular Medicine can be found at:

Email Alerts: http://vmj.sagepub.com/cgi/alerts

Subscriptions: http://vmj.sagepub.com/subscriptions

Reprints: http://www.sagepub.com/journalsReprints.nav

Permissions: http://www.sagepub.com/journalsPermissions.nav

Citations: http://vmj.sagepub.com/content/15/5/433.refs.html

>> Version of Record - Oct 6, 2010

What is This? 
Images in vascular medicine

Renal arteriovenous fistula

Johannes Jacobi', Karl F Hilgers', Werner Lang',

Kai-Uwe Eckardt' ${ }^{\prime}$ and Michael Uder ${ }^{3}$

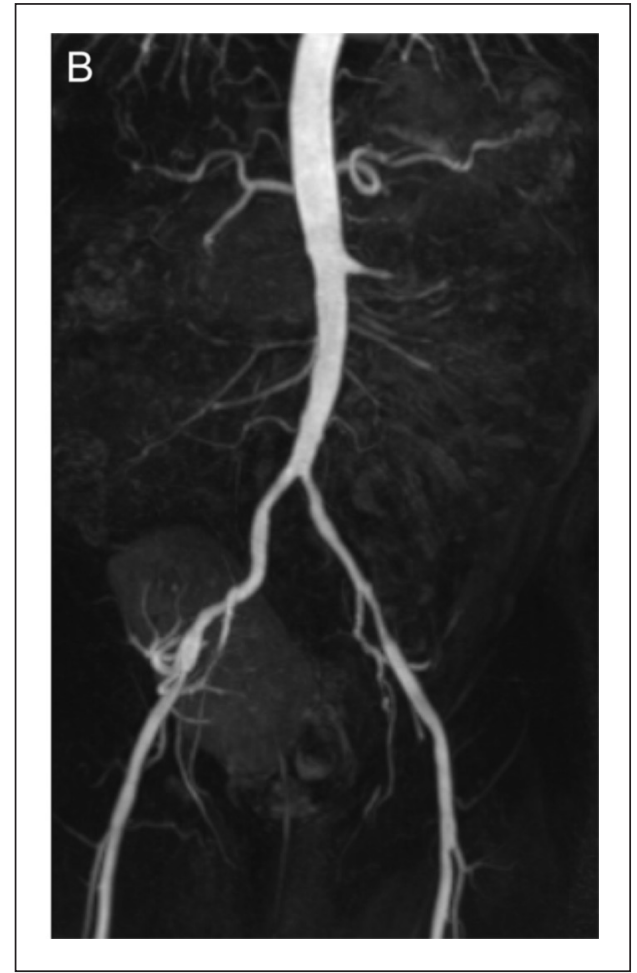

Panel B
Vascular Medicine I5(5) 433-434 (C) The Author(s) 2010 Reprints and permission: sagepub. co.uk/journalsPermissions.nav DOI: $10.1177 / 1358863 \times 10376000$ http://vmj.sagepub.com

(SSAGE
Panel A

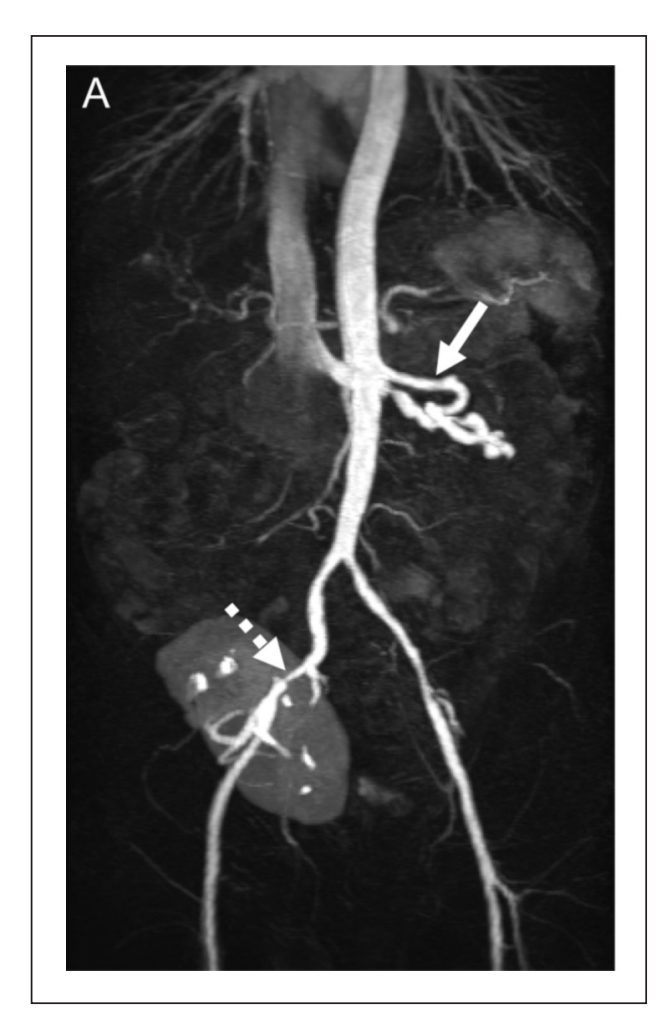

A 46-year-old man presented with intermittent claudication of both legs and dyspnea on exertion. His pain-free walking distance was below $200 \mathrm{~m}$. In 1979, a diagnosis of IgA-nephropathy was established following an open leftsided renal biopsy. His kidney disease was progressive and from 1984 until 1993 the patient underwent chronic hemodialysis. In 1993, he received a renal allograft into the right iliac fossa. His current serum creatinine is $1.28 \mathrm{mg} / \mathrm{dl}$. Upon presentation pulses were palpable in both ankles. Blood pressure was $130 / 80 \mathrm{mmHg}$. The ankle-brachial index of the right and left leg were 0.80 and 0.85 , respectively. Owing to his symptoms magnetic resonance angiography of the aorta and both legs was performed. Angiography revealed a large arteriovenous fistula of the left kidney (solid arrow) with rapid filling of the inferior vena cava (Panel A). In addition, a stenosis of the right external iliac artery proximal to the renal transplant was noted (dashed arrow, Panel A). The patient underwent coiling of the renal arteriovenous fistula and balloon angioplasty of the stenosis. A follow-up magnetic resonance angiogram 3 months later revealed complete closure of the fistula and no

\footnotetext{
' Department of Nephrology and Hypertension, University of ErlangenNuremberg, Erlangen, Germany

${ }^{2}$ Department of Vascular Surgery, University of Erlangen-Nuremberg, Erlangen, Germany

${ }^{3}$ Institute of Radiology, University of Erlangen-Nuremberg, Erlangen, Germany
}

\section{Corresponding author:}

Johannes Jacobi

Department of Nephrology and Hypertension

University of Erlangen-Nuremberg

Krankenhausstr. 12

91054 Erlangen

Germany

E-mail: johannes.jacobi@uk-erlangen.de 
evidence of restenosis of the iliac artery (Panel B). Symptoms of intermittent claudication had resolved, and the ankle-brachial index was I.2 in both legs.

Given the long duration between the open renal biopsy and development of symptoms, it remains unknown whether the arteriovenous fistula was caused by the biopsy or developed spontaneously at a later time. Arteriovenous fistula is a frequent vascular complication of renal biopsy, with an estimated risk of approximately $10 \%$.' In most cases, iatrogenic arteriovenous fistulas disappear spontaneously and embolization is seldom necessary.

\section{Reference}

I. Schwarz A, Hiss M, Gwinner W, Becker T, Haller H, Keberle $M$. Course and relevance of arteriovenous fistulas after renal transplant biopsies. Am J Transplant 2008; 8: 826-831.

'Images in vascular medicine' is a regular feature of Vascular Medicine. Readers may submit original, unpublished images related to clinical vascular medicine. Submissions may be sent to: Mark A Creager, Editor in Chief, Vascular Medicine, via the web-based submission system at http://mc.manuscriptcentral.com/vascular-medicine 